\title{
Plans for Solving the Problems of Residents of Gamcheon Culture Village with Design Thinking
}

\author{
Na-Rang Kim **, Soon-Goo Hong** and Sang-Jin Lee*** \\ * Business Research Center, Dong-A University, Busan, Korea \\ E-mail:whitecoral@hanmail.net \\ ** Department of Management Information Systems, Dong-A University, Busan, \\ Korea \\ E-mail: shong@dau.ac.kr \\ *** KAMCO, Busan, Korea \\ E-mail:acroman@daum.net
}

\begin{abstract}
Design thinking is a next-generation problem-solving method that global companies, such as SAP and Google, use to manage innovation. Design thinking is a human-oriented method of finding and searching for solutions in which the many interested parties related to the problem participate. This method is being broadly used in diverse corporate and social areas. This study investigated problems that residents in urban regeneration regions are facing and tried to solve these problems through the application of design thinking. This study specifically targeted Gamcheon Culture Village, which is known as a successful case of urban regeneration. The study participants identified the fundamental problems behind the inconveniences that the residents in urban regeneration regions were experiencing. Differing from existing problem-solving processes, design thinking could provide an opportunity for mutual understanding through the gathering of many interested parties to empathize with the residents' troubles, define problems, and search for solutions. This study proved that the most important success factor for urban regeneration projects was a common goal for the related interested parties, including residents, and the sharing of created values. This study's academic contributions were its application of design thinking for the first time to a case that involved multiple interested parties that were related to urban regeneration project, consequently inducing future studies. Practically, the study provided a problemsolving methodology that relevant institutions can apply when developing policies regarding urban regeneration projects.
\end{abstract}

Keywords: SAP, Design Thinking, Gamcheon Culture Village, Regional Innovation, Regional Regeneration

\section{Introduction}

To solve the population concentration and housing problems caused by the urbanization, Korea has focused on the development of new cities after the 1980s. As a result, population decreased in older cities, and economic grounds inside these cities were lost. The buildings and infrastructure in the downtown areas of these older cities became

\footnotetext{
***Corresponding author: Soon - Goo Hong

Department of Management Information Systems,

Dong-A University,

225, Gudeok-ro, Seo-gu, Busan, 49236, Republic of Korea

E-mail: shong@dau.ac.kr
} 
obsolete, putting older cities in an inferior position.

Despite the nationwide fame that Gamcheon Culture Village acquired as an urban regeneration case, the urban regeneration's positive effects on residents' quality of life were not significant [1]. According to the results of a survey of 200 residents who lived in Gamcheon Culture Village for more than a year and 200 tourists from outside the village, $64.5 \%$ of the residents replied that they "do not have pride as a resident in Gamcheon Culture Village," and 51.5\% of the residents replied that "village asset value did not increase." In particular, $66.0 \%$ of the residents replied that "village vitalization did not increase employment." As such, the residents' living satisfaction dropped, and their community activity became passive after the urban regeneration project, which was centered at attracting tourists with the town's wall paintings. This happened because the urban regeneration policy was focused on the satisfaction of interested parties rather than residents. This policy direction needs to change for sustainable urban regeneration to be achieved.

This study intended to use design thinking to examine these problems. Design thinking developed from the philosophy and interest of President Plattner of the global IT company SAP. Differing from existing problem-solving methods, design thinking focuses on understanding the nature of problems centered on human beings through the participation of multiple interested parties. This method can effectively solve problems that appear in the process of building and applying the existing urban regeneration model. Design thinking received attention as a next-generation problem-solving method, and this method has been used to solve corporate and social problems through analytic and intuitive thoughts. For example, global information communication technology companies, such as SAP and Google, have used design thinking as a means of management innovation [2]. By applying design thinking, this study attempted to investigate the problems that residents in urban regeneration perceive through empathizing with the parties affected by the urban regeneration and proposing solutions to these problems.

\section{Previous Literature}

\subsection{Urban Regeneration and Gamcheon Culture Village}

Development focused on economic growth, represented by the Saemaul Movement in the 1970s, has produced side effects, such as regional imbalance and the deviation and isolation of residents. To solve these problems, local governments have used the historical and spatial characteristics and values that each region possesses as cultural content to attract residents and outsiders, which is a strategy that has aimed at balancing the growth of cities through urban regeneration [3]. Recently, culture-oriented urban regeneration projects are receiving increasing attention. Gamcheon Culture Village is counted as the most representative model of success of these culture-oriented projects.

Gamcheon Culture Village is located in Gamcheon-dong, Saha-gu in Busan Metropolitan City. In the 1950s, Taegeukdo devotees and Korean War refugees gathered to form the town. In the past, the region had a reputation as having fallen behind with its development under the name of Taegeukdo Village. At the end of the 20th century, Gamcheon region, which used to be the old downtown area of Busan, was gradually becoming a slum; people were leaving the town due to new city development and industrialization, and the number of vacant houses was rapidly increasing.

However, Gamcheon Culture Village began to transform itself through art projects beginning in 2009. Currently, beautiful wall paintings and sculptures are displayed all over the village. Through a series of projects, including the Dreaming Machu Picchu project in 2009, the Miromiro Alley project in 2010, the Sanbokdoro Renaissance project 
in 2011, and the Twice the Pleasure project in 2012, the village was transformed to its current shape [4]. The village, which is located in the foot of Cheonmasan Mountain, obtained nationwide reputation for the harmony of its narrow alleys and old low-rise houses. The village came to be known as Gamcheon Culture Village as small cafes and shops opened in the village. The village's selection for the village art promotion project of the Ministry of Culture, Sports and Tourism in 2009 was a key moment for Gamcheon Culture Village. After the village's selection for the Ministry's project, artists and residents in the Busan area who lived in Gamcheon Culture Village collaborated to revitalize the region by harmonizing the existing facilities and environment, growing out of an indiscrete urban reconstruction project. Thus, the town became a role model for urban regeneration projects.

Moreover, the town was selected as one of the 100 best spots for travel in Korea for two consecutive years and received the 2016 Beautiful Village Art award and the Excellent Education City award. CNN also introduced the town as "the most artistic village in Asia [5].

\subsection{Design Thinking}

Design thinking refers to a process of producing outcomes through repeated divergent thinking that searches for alternative solutions based on observations, empathy, and searching for methods that fit a given situation. Design thinking is a methodology that can satisfy the issues of customization and individuation that are necessary to meet diverse human needs. This method enhances diverse life values through empathy and contemplation on human life and the situations that take place during a person's life [6]. IDEO, which is known as an innovative company that is representative of design thinking, defined design thinking as "a way of thinking that uses designers' sensitivity and working method for the purpose of satisfying technically applicable business demands where consumers can make valuable assessment and use market opportunity" [7]. Design thinking attempts to solve realistic problems based on the theory regarding the ways of thinking by designers. Design thinking is particularly important for product or service innovation. Its advantage is its applicability to an entire product and service and to an overall process, covering, planning, marketing, and development, rather than being limited to superficial design.

The Stanford design thinking process consists of five stages: empathize, define, ideate, prototype, and test [8]. The first stage involves observing customers or users and forming bonds of empathy with them to identify the true problem. When facing the problems that have been carefully defined through these empathetic bonds, participants produce possible solutions through brainstorming. After bringing the best ideas together, a prototype, which is a process of visualization, is manufactured [9]. Finally, the manufactured prototype undergoes testing by many interested parties and receives feedback. This process repeats. 


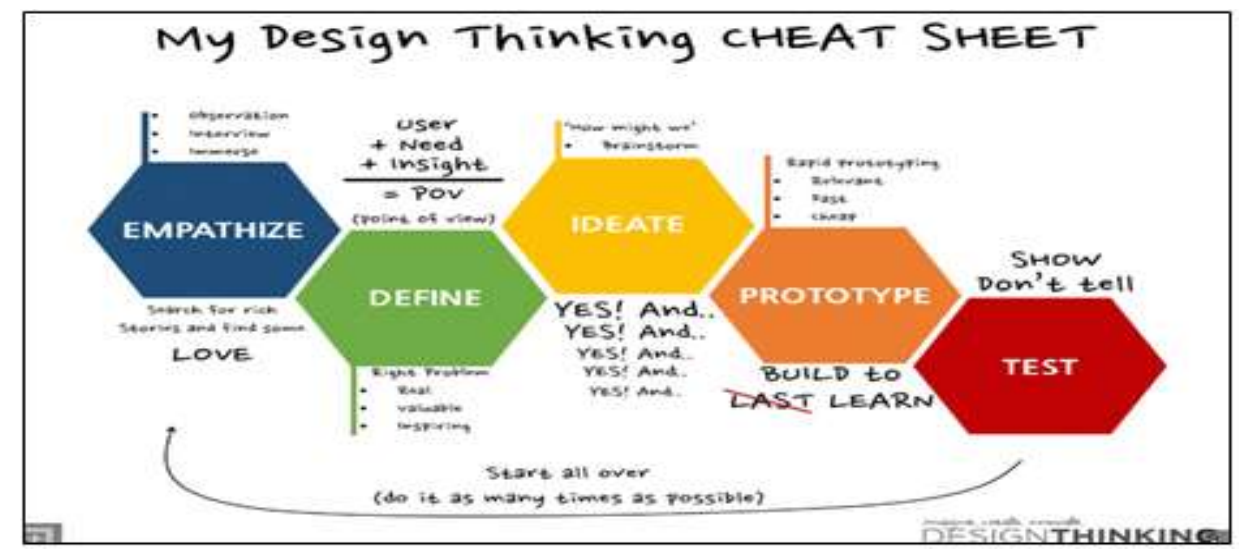

Figure 1. The Five Stages of Design Thinking

\section{Research Design}

\subsection{Applying Design Thinking to Regional Regeneration Cases}

As the annual number of visitors to Gamcheon Culture Village exceeded one million following its selection for the village art promotion project of the Ministry of Culture, Sports and Tourism in 2009, residents' discontent began to appear. Although residents expected the increase in the number of tourists and the consequent economic revitalization would make the residents wealthier, the economic profit was not linked to the residents. As the revitalization infused new life to the deteriorated old downtown area, gentrification began to appear, and the existing low-income residents were driven out of the area. Due to the close proximity of tourist spots and residential areas in the village, residents could not rest at home because tourists would take photos of the residents' houses without permission. The village was always restless, and the surrounding traffic conditions seriously worsened. Residents' complaints were more common than ever.

We attempted to derive ideas that can solve the difficulties that the residents in Gamcheon Culture Village were facing and investigate the current state of regional regeneration through the application of design thinking. For this purpose, the design thinking facilitator team found people from diverse classes who were identified by the analysis of the interested parties and cohosted the workshop with the resident committee.

The workshop opened from 9 am to $7 \mathrm{pm}$ on October 8, 2016. Observations and interviews were conducted multiple times prior to the workshop.

Table 1. Team Composition of Design Thinking Workshop

\begin{tabular}{ccc}
\hline \multirow{2}{*}{ Team } & $\begin{array}{c}\text { Compositio } \\
\mathrm{n}\end{array}$ & Characteristics \\
\hline & Residents & Resident Committee \\
\cline { 2 - 3 } & Professor & $\begin{array}{c}\text { Regional Regeneration Expert From Gamcheon Culture } \\
\text { Village }\end{array}$ \\
\cline { 2 - 3 } 1 & Tourists & Local University \\
\cline { 2 - 3 } & Companies & Local Companies \\
\cline { 2 - 3 } & Facilitator & Design Thinking Expert \\
\cline { 2 - 3 } & Residents & Resident Committee \\
\cline { 2 - 3 } & Tourists & Local University \\
\cline { 2 - 3 } & Tourists & Local University \\
\hline
\end{tabular}




\begin{tabular}{cc}
\hline Expert & Regional Regeneration \\
\hline Facilitator & Design Thinking Expert And University Professor \\
\hline
\end{tabular}

\subsection{Empathy and Problem Definition Stages}

The problems were defined in each group by compiling the observation and interview results, as defined by the design thinking scheme. The definition stage is the stage in which the empathy outcomes from the observation and interview results were compiled and the coverage was defined. In the empathy stage, team members defined the problem by integrating the perceived problems identified in the interviews with users. Here, the point of view scheme, which asks about a user's point of view, was used.

The first group identified problems caused by the lack of separation between the residential and tourist areas, which resulted in invasions of privacy, inconvenient parking, traffic troubles, noise pollution, environmental problems, resident welfare issues, building a relationship with the neighboring village, and the necessity of creating unique culture in Gamcheon Culture Village. Among these issues, the largest problem was that the tourist and residential areas had no clear distinctions. Therefore, changing the tourists' perceptions of Gamcheon Culture Village from a place for tourism to a place to visit was determined to be urgent.

In second group, insufficient funds, low tourism revenue, and the low tourism-based income for the residents despite the diverse inconveniences the residents faced due to the increasing number of tourists were discussed. Here, the goal of the problem-solving was to develop tourism profits that could be returned to the residents of Gamcheon Culture Village.
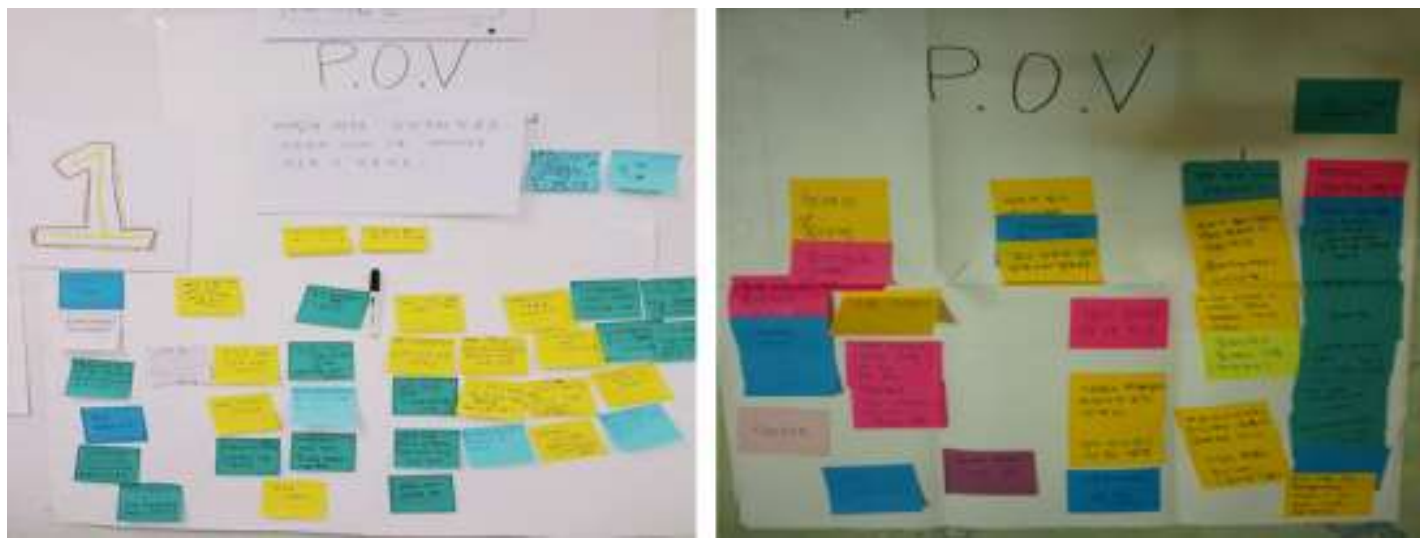

Figure 2. The Point of View (POV) Stage

\subsection{Ideation, Prototype, and Test Stages}

The first group redefined the question of how to induce the mutual consideration of visitors and residents in Gamcheon Culture Village for each other. As a solution, the group chose an idea of creating a certain theme for alleys that can be used to distinguish between the residential and tourist areas.

After brainstorming about how to develop content that can help the residents profit from the tourism in the region, the second group suggested that the residents could produce things that can only be made or eaten in Gamcheon Culture Village. In addition, buses that could be linked to tourism revenue, puzzle-making using the village's side streets, the installation of escalators, the acceptance of donations for village development, and an accommodation project using vacant houses were highly ranked as potential solutions. Afterward, a prototype for visualization was manufactured using diverse 
methods to obtain opinions about each idea.

The first group helped improve the mutual consideration of the villagers and tourists by marking special themed sections of the village on the village map brochure, which is currently on market, where residents and tourists can coexist. In the test results, one enhancement was proposed that promoted the change of perception from tourist spots to their original meaning as residential areas. To implement this enhancement, implementable space, name changes, and plans for promotion were suggested. The second group produced a variety of goods with characteristics unique to Gamcheon's environment and presented these goods as prototypes. In the test results, ideas and specialties that emphasized the water in Gamcheon were proposed as possible enhancements to the prototypes.

\section{Conclusion}

This study attempted to use design thinking to identify the fundamental problems that residents in Gamcheon Culture Village were facing by meeting with the residents and diverse interested parties. Through the empathizing process, the participants investigated the current situation of regional regeneration and proposed solutions to the existing issues.

According to the results the design thinking process, the residents were facing three main problems. The most fundamental problem was that the residential and tourist areas were not distinct from each other in Gamcheon Culture Village. As a result, residents' inconvenience ironically increased in proportion to the increase of tourists. Second, since the residents' quality of living was low due to insufficient residential infrastructure, their satisfaction with the urban regeneration was not high. Third, even though numerous tourists visited Gamcheon Culture Village, their visits did not contribute to the residents' income because the visitors to Gamcheon Culture Village consumed as little as $800 \mathrm{KRW}$ per person. In addition, an inflow of outsiders caused gentrification.

Several solutions to these issues were proposed. First, a change of the tourists' perception of the area was necessary for the coexistence of residential and tourism areas. Ideas were proposed to arrange sections of the village that could be easily distinguished between residential and tourist areas. With this change, tourists and residents could coexist because tourists could enjoy storytelling-type tourism that incorporates the people and lives that are exclusive to Gamcheon Culture Village, which would differentiate the village from other commercial tourist spots without negatively impacting the residents' lives. Second, the goal of the urban regeneration project should be village vitalization through the enhancement of residents' living environment rather than through tourism. Growing out of the existing policy, which is focused on the quantitative expansion of tourists, the goal of this policy should be a return to the fundamental purpose of urban regeneration, which is the enhancement of residents' living conditions, by preparing welfare facilities and infrastructure. Policies that can return the profits from the tourism vitalization to the residents of the village are also necessary. Third, a successful model of sustainable urban regeneration can be achieved if a resident income-boosting policy and a gentrification-prevention policy are prepared. To create profits for residents, ideas for unique tangible and intangible services and products that echo the unique historical story and diverse content of Gamcheon Culture Village are required. Policies aimed at preventing gentrification and promoting coexistence with outsiders are also required.

Design thinking is a method of searching for solutions that work for the multiple interested parties that are related to a problem using a human-oriented viewpoint. This study has shown that the fundamental problems regarding the inconvenience for residents living in urban regeneration regions can be identified through design thinking.

Differing from existing problem-solving processes, with design thinking, multiple 
interested parties, including residents, tourists, and other relevant organizations, could work together to identify the residents' hidden needs through the empathizing stage, which pursues a deep understanding of the behaviors, thoughts, and emotions of users in a certain situation. This stage provides an opportunity for mutual understanding through the definition of problems and the search for solutions. Meanwhile, the most important success and sustenance factor in the urban regeneration project was the common goals and shared values of the interested parties, including residents. This study has shown that showy quantitative expansion policies should be rejected when planning relevant policy, and residents' position as the root of urban regeneration should not be forgotten when developing these policies.

This study's academic contribution is based on its application of design thinking during a workshop in which various interested parties linked with this urban regeneration project participated. Practically, the study can be used as a guideline for problem solving that relevant institutes can apply when developing urban regeneration policy. The study has limitations in that we could not receive diverse feedback and evaluation from the residents due to the short research period. Another shortcoming of the study is that it lacks objectivity, being a qualitative case study. We expect that diverse quantitative studies will follow in the future that can address these limitations.

\section{Acknowledgments}

This work was supported by the Ministry of Education of the Republic of Korea and the National Research Foundation of Korea (NRF-2015S1A3A2046781).

\section{References}

[1] J. Y. Yoon, "Study on Urban Regeneration Village Branding Strategies: Focused on Gamchen Culture Village", Busan Development Institute, (2016).

[2] S. G. Yang, "Design Thinking': Case Studies and Implementation Method", Theses Master, KAIST, (2015).

[3] J. R. Choi, "Book Culture Space and City Play: Focusing on the Book Culture Space in front of Hongdae", Han-Kuk University of Foreign Studies Knowledge Publisher, (2016).

[4] S. W. Lee, "A Study on the Improvement of Brand in Gamcheon Culture Village", Theses Master, Dong-A University, (2017).

[5] Weekly Empathize, "Seven Alleys in Our Neighborhood That Bloomed with Public Art", The Sympathy Culture Scene, vol. 1, no. 13, (2017).

[6] S. Y. Lim, "Study on Interdisciplinary Art Education Framework based on Design Thinking", theses Master, Sungkyunkwan University, (2016).

[7] T. Brown, "Design Thinking, Harvard Business Review", (2008).

[8] H. Plattner, "An Introduction to Design Thinking Process Guide", The Institute of Design at Stanford: Stanford, (2010).

[9] S. H. Park, S. OH, J. S. Park and M. K. Lee, "A Unified Model of Action Learning and Design Thinking for Social Innovation”, Venture Entrepreneurship Research, vol. 11, no. 2, (2016), pp. 89-100. 
International Journal of $u-$ and e- Service, Science and Technology Vol.10, No.6 (2017) 